\title{
Dopamine receptors and sleep induction in man
}

\author{
S. B A S S I, M. G. A L B I ZZ A T I, L. F R A T T O L A, \\ D. PASSERINI, A N D M T RABUCCHI
}

From the Department of Neurology, University of Milan, and the Department of Pharmacology and Therapeutics, University of Brescia, Italy

SUMMARY Sleep induction has been studied in humans after the administration of apomor- $\frac{\overline{\bar{N}}}{\bar{N}}$ phine, a direct stimulant of the central dopaminergic system. The drug induced sleep and $\stackrel{\Phi}{\circ}$ vomiting in healthy volunteers while it had no significant effect on 10 Parkinsonism patients treated for a long period with L-dopa. Apomorphine given to a group of Parkinsonism patients $\vec{\circ}$ not receiving any specific treatment, and with a lower degree of disease severity, induced vomiting and sleep with a pattern similar to that in healthy subjects. A relationship between $\bar{\omega}$ the dopaminergic system and sleep induction is suggested.

Various authors have recently identified dopaminergic neurones and dopaminergic receptors in cerebral structures other than the nigrostriatal system-limbic system, some cortical and some hypothalamic-hypophyseal areas (Kebabian et al., 1972; Horn et al., 1974; Sourkes, 1975; ClementCormier, 1977). These observations suggest that the dopaminergic system may play, among other physiological activities, an important role in sleep.

We have studied sleep induction in man after administration of apomorphine. This drug, at the dose we have used, is a direct stimulant of the dopaminergic receptors at various levels, and it has been proved to induce sleep probably in relation to the stimulation of these non-emetic receptors (Sagales and Erril, 1975; Di Chiara et al., 1976; Corsini et al., 1977).

We administered apomorphine to subjects with a variety of responsiveness of the dopaminergic systems. Three groups of 10 volunteer subjects have been investigated: normal control subjects, Parkinsonism patients before the beginning of any specific treatment, and Parkinsonism patients undergoing L-dopa therapy over a long period. One may suppose that these patients have different dopaminergic receptor responsiveness, in relation not only to the severity of the illness, but also to the chronic treatment with high doses of L-dopa (Barbeau, 1974; Pycock and Marsden, 1977; Lee et al., 1978).

Address for correspondence and reprint requests: Dr S. Bassi, Department of Neurology, Pad. Ponti-Policlinico, Via F. Sforza 35, 20122 Milan, Italy.

Accepted 1 November 1978

\section{Subjects and methods}

The study was carried out on 10 normal control subjects (six men and four women) aged 46-67 years (mean $=54 \pm 4.7$ ) and on 20 patients wit Parkinsonism. The last group was divided into two subgroups. The first consisted of 10 patients (s men and four women) aged 51-72 years (mean 훙. $\overrightarrow{0}$ $61.6 \pm 5.5$ ) on L-dopa plus carbidopa therapy fơ co at least 18 months, with duration of illness varying from three to 20 years and a severity, rated on the Webster scale, ranging from 16 to 6 (mean $=12 \pm \frac{\partial}{\partial}$ 2.6). The second group consisted of 10 patients (five men and five women) aged 50-61 years (mean $\stackrel{0}{\circ}$ $=54.4 \pm 3.4$ ), who had never been treated with L-dopa-their illness had lasted from five to 12 응 months, with a mean severity of $4 \pm 0.9$ on the Webster scale.

The nature and purpose of the investigation were explained to the patients and control subjects, and their consent was obtained. Recordings of EEG, EMG (from submental muscle), electrooculogram, cardiac and respiration rates were made on each subject, beginning between 1600$1700 \mathrm{hr}$ for three hours after subcutaneous injection of apomorphine $(1.5 \mathrm{mg})$. Patients and 옥 control subjects were submitted to a similar $D$ experiment three days before apomorphine administration, but with saline injected as placebo.

Our selected apomorphine dose is the lowest emetic one in normal subjects, and it is also the $N$ dose which acts as stimulant to dopaminergic $\underset{\omega}{\mathrm{N}}$ (DA) receptors (Duby et al., 1972; Tolosa and Sparber, 1974). 
The EEG was recorded from longitudinal inferior and vertex reference leads. The paper speed was $15 \mathrm{~mm} /$ second.

We recorded the appearance of vomiting and its latency, sleep onset latency, and stages of sleep.

\section{Results}

In all normal subjects apomorphine induced both vomiting and sleep (Table). Mean latency time was 25.6 \pm 1.94 minutes for vomiting (range 15$35 \mathrm{~min}$ ) and $31.3 \pm 1.89 \mathrm{~min}$ for sleep (range 22$39 \mathrm{~min}$ ); the mean duration of the sleep induction by the drug was $107.6 \pm 8.18 \mathrm{~min}$ (range 75-140 min). The associated sleep EEG was fairly homogeneous in all normal subjects: stages 3 and 4 were reached quickly, and their duration was $30 \%$ of the record. No REM sleep was recorded.

Among the 10 Parkinsonism patients treated with L-dopa, apomorphine $(1.5 \mathrm{mg})$ induced vomiting in two, and nausea in another one, while sleep was induced in three subjects but in only one with a latency comparable to that of the control subjects (Table).

In the group of Parkinsonism patients who had never had L-dopa treatment and who had a less severe degree of disease, apomorphine induced vomiting and sleep with a mean latency of $23.7 \pm$ $2.1 \mathrm{~min}$ (range 15-34 $\mathrm{min}$ ) for vomiting and 29.8 $\pm 2.31 \mathrm{~min}$ (range $24-39 \mathrm{~min}$ ) for sleep. The latencies were not significantly lower than in control subjects (Table). Stages 3 and 4 sleep were quickly recorded and they lasted for about 34\% of the recording time. In one case REM stage sleep occurred and the patient was wakened by the operator at the end of the third hour of registration.

\section{Discussion}

The role of dopamine and of substances acting on the dopaminergic system in sleep mechanisms has been investigated in animals (Kafi and Gaillard, 1976) and in humans (Sagales and Erill, 1975; Corsini et al., 1977), but without explanation of the results.

In our study, apomorphine, at a dosage of 1.5 mg subcutaneously, induced in healthy volunteers, vomiting and sleep with latency, duration, and EEG patterns which were homogeneous in all subjects. Under the same experimental conditions, the drug did not induce either vomiting or sleep in seven of 10 patients suffering from Parkinson's disease who had been taking L-dopa for a long time. It is important to note that in patients of this group the drug did not provoke an improvement of the Parkinsonism symptoms, in contrast with observations reported in the literature (Duby et al., 1972). Furthermore, in two of them with a severe degree of illness, and, therefore, receiving a bigger dosage of L-dopa, apomorphine induced some excitation.

In the normal subject, apomorphine induces vomiting by stimulating the dopaminergic receptors of the emetic centre in the medulla oblongata (Sourkes, 1975); it probably induces sleep by stimulating the hypothalamic-hypophyseal neuroendocrine centres.

The lack of response to apomorphine found in patients with severe Parkinsonism on treatment for a long time may be related to the treatment itself. Numerous observations, including the recent ones of Lee et al. (1978) show that long-term treatment with L-dopa reverses the supersensitivity phenomenon of the striatal dopaminergic re-

Table Vomit and sleep induction times after apomorphine injection in three different groups of subjects

\begin{tabular}{|c|c|c|c|c|c|c|c|c|c|c|c|}
\hline \multicolumn{4}{|c|}{ Control subiects } & \multicolumn{4}{|c|}{ Parkinsonism under treatment } & \multicolumn{4}{|c|}{ Untreated Parkinsonism } \\
\hline & $\begin{array}{l}\text { Vomiting } \\
\text { latency } \\
(\min )\end{array}$ & $\begin{array}{l}\text { Sleep } \\
\text { latency } \\
(\mathrm{min})\end{array}$ & $\begin{array}{l}\text { Sleep } \\
\text { time } \\
(\mathrm{min})\end{array}$ & & $\begin{array}{l}\text { Vomiting } \\
\text { latency } \\
(\min )\end{array}$ & $\begin{array}{l}\text { Sleep } \\
\text { latency } \\
(\text { min) }\end{array}$ & $\begin{array}{l}\text { Sleep } \\
\text { time } \\
(\min )\end{array}$ & & $\begin{array}{l}\text { Vomiting } \\
\text { latency } \\
(\text { min })\end{array}$ & $\begin{array}{l}\text { Sleep } \\
\text { latency } \\
(\mathrm{min})\end{array}$ & $\begin{array}{l}\text { Sleep } \\
\text { time } \\
\text { (min) }\end{array}$ \\
\hline CF & 20 & 35 & 75 & PP & - & - & - & $\mathrm{CS}$ & 26 & 36 & 81 \\
\hline RD & 35 & 38 & 107 & SF & - & - & - & PG & 15 & 20 & 140 \\
\hline BS & 15 & 22 & 140 & BE & - & - & - & MA & 20 & 24 & 180 \\
\hline DR & 22 & 25 & 78 & MG & - & - & - & PM & 17 & 20 & 160 \\
\hline $\mathbf{A C}$ & 25 & 39 & 135 & BP & 35 & 55 & 90 & LA & 34 & 39 & 102 \\
\hline DD & 29 & 32 & 95 & BS & 22 & 31 & 100 & CF & 21 & 24 & 137 \\
\hline GS & 34 & 36 & 134 & ML & - & - & - & NC & 34 & 38 & 101 \\
\hline TC & 23 & 24 & 83 & FS & - & - & - & MC & 19 & 31 & 168 \\
\hline HS & 26 & 32 & 119 & $\mathbf{R} \mathbf{R}$ & 36 & 58 & 114 & RV & 27 & 35 & 75 \\
\hline Mean & 25.6 & 31.3 & 107.6 & & & & & & $23.7^{*}$ & $29.8^{*}$ & $121.8^{*}$ \\
\hline$\pm \mathbf{S E}$ & 1.94 & 1.89 & 8.18 & & & & & & 2.1 & 2.31 & 12.69 \\
\hline
\end{tabular}

$*=P$ versus controls $=$ NS. 
ceptors. We consider it possible that the high doses of L-dopa administered may alter the response even in extrastriatal receptors, such as those of the neuroendocrine and emetic centres. One may explain in this way, not only the lack of therapeutic effect of apomorphine on the Parkinsonism symptoms, but also its incapacity for inducing vomiting and sleep as a consequence of the functional changes caused by dopamine on the receptors of the neuroendocrine and emetic centres.

Support for this hypothesis comes from the behaviour of untreated Parkinsonism and patients with less severe Parkinsonism. In these patients apomorphine induced vomiting and sleep with similar parameters to the control subjects, and also provoked an improvement of the Parkinsonism symptoms.

This drug response seems to confirm that in this group of patients the altered receptor function is limited to the striatal structures rendered supersensitive by degeneration of the nigral cells.

Studies are in progress to clarify the effects that DA system stimulation may produce on various sleep stages overnight and to indicate further biochemical steps (De Wied, 1977) and the anatomical structures involved in sleep induction.

\section{References}

Barbeau, A. (1974). The clinical physiology of side effects in long term L-dopa therapy. Advances in Neurology, 5, 347-355.

Clement-Cormier, Y. C. (1977). Adenylate cyclase from various dopaminergic areas of the brain and the action of antipsychotic drugs. Biochemical Pharmacology, 26, 1719-1722.

Corsini, G. U., Del Zompo, M., Manconi, S., Piccardi, M. P., Onali, A., and Gessa, G. L. (1977). Evidence for dopamine receptors in the human brain mediating sedation and sleep. Life Sciences, 20, 1613-1618.

De Wied, D. (1977). Peptides and behavior. Life Sciences, 20, 195-204.
Di Chiara, G., Porceddu, M. L., Vargiu, L., Argiolas, A., and Gessa, G. L. (1976). Evidence for dopamine receptors mediating sedation in the mouse brain. Nature, 264, 564-567.

Duby, S. E., Cotzias, G. C., Papavisiliou, S. P., and Lawrence, H. W. (1972). Injected apomorphine and orally administered levodopa in Parkinsonism. Archives of Neurology (Chicago), 27, 474-480.

Horn, A. S., Cuello, A. C., and Miller, R. J. (1974). Dopamine in the mesolimbic system of the rat brain: endogenous levels and the effects of drugs on the uptake mechanism and stimulation of adenylate cyclase activity. Journal of Neurochemistry, 22, 265-270.

Kafi, S., and Gaillard, J. M. (1976). Brain dopamine receptors and sleep in the rat: effects of stimulation and blockade. European Journal of Pharmacology, 38, 357-363.

Kebabian, J. W., Petzold, G. L., and Greengard, P. (1972). Dopamine-sensitive adenylate cyclase in the caudate nucleus of rat brain and its similarity to the dopamine receptor. Proceedings of the National Academy of Sciences of the United States of America, 69, 2145-2149.

Lee, T., Seeman, P., Pajput, A., Tarley, I., and Hornykiewicz, O. (1978). Receptor basis for dopaminergic supersensitivity in Parkinson's disease. Nature, 273, 59-61.

Pycock, J., and Marsden, C. D. (1977). Central dopa minergic receptors supersensitivity and its relevanc8 to Parkinson's disease. Journal of the Neurologicat Sciences, 31, 113-121.

Sagales, T., and Erill, S. (1975). Effects of centrat dopaminergic blockade with pimozide upon the EEG stages in man. Psychopharmacologia, 41, 5361.

Sourkes, T. L. (1975). Neural and neuroendocrine functions of dopamine. Psychoneuroendocrinology, 1, 69-78.

Tolosa, E. S., and Sparber, G. B. (1974). Apomorphine in Huntington's chorea: clinical observations and theoretical considerations. Life Sciences, 15, 1371-1380. 